Disponível em:

http://editora.unoesc.edu.br/index.php/race

Race, Joaçaba, v. 15, n. 1, p. 157-174, jan./abr. 2016

\title{
EFEITOS DO USO DA INFORMAÇÃO EDIÇÃO LIMITADA SOBRE PERCEPÇÕES DE PREÇO E INŢENÇÃO DE COMPRA DE PRODUTOS
}

\section{Effects of the use of the information limited edition on perceptions of price and product purchase intention}

Sandro Dias Selau

E-mail: sandroselau@gmail.com

Especialista em Marketing Estratégico, Gestão Empresarial e Gestão de Vendas; Graduado em Publicidade com Ênfase em Marketing pela Escola Superior de Propaganda e Marketing; Gestor em indústria privada na área de Trade Marketing. Endereço para correspondência: Rua Guilherme Schell, 350, Santo Antônio, 90640040, Porto Alegre, Rio Grande do Sul, Brasil.

Leandro Miletto Tonetto

E-mail: ltonetto@gmail.com

Doutor em Psicologia (Área de Cognição Humana) pela Pontifícia Universidade Católica do Rio Grande do Sul; Mestre em Psicologia Social e da Personalidade pela Pontifícia Universidade Católica do Rio Grande do Sul; Professor do Programa de Pós-graduação em Design da Unisinos.

Artigo recebido em 27 de julho de 2015. Aceito em 01 de dezembro de 2015. 
Resumo

A escassez de um produto tem demonstrado impacto no aumento da percepção de valor e na intenção de compra dos consumidores. Nesse contexto, propagandas que enfatizam escassez por suprimento (edições limitadas) tendem a ser menos persuasivas que as que evidenciam a indisponibilidade de produtos por alta demanda. Com o objetivo de esclarecer a força do aspecto comunicacional do simples uso da expressão edição limitada, no presente estudo investigouse o impacto isolado da informação de que um produto se trata de uma edição limitada no comportamento do consumidor. Em um experimento, foi manipulada a presença da informação edição limitada na descrição de uma série de produtos apresentados a estudantes universitários ( $\mathrm{N}=130)$. Os resultados indicaram o efeito do uso da expressão na disposição para pagar e na intenção de compra dos consumidores. As pessoas expostas à informação de que os produtos se tratavam de uma edição limitada atribuíram valores superiores a eles e, em alguns casos, maior intenção de compra nos 30 dias seguintes, em comparação com consumidores que não foram informados sobre o fato. As implicações teóricas e gerenciais são discutidas, enfatizando que a expressão apresenta um efeito comunicacional na valorização de produtos, mas não implica, necessariamente, aumento da intenção de compra.

Palavras-chave: Edições limitadas. Escassez. Comportamento do consumidor. Estratégia de marketing. Promoção de vendas.

\title{
Effects of the use of the information limited edition on perceptions of price and product purchase intention
}

\begin{abstract}
Product scarcity has shown impact on consumer's perception of value and purchase intention. In this context, advertising that emphasizes scarcity due to limited supply (limited editions) tend to be less persuasive than that in which the actual unavailability due to high demand is indicated. Aiming at understanding the communicational aspect of the simple use of the expression limited edition, the present study investigated the isolated effect of the information that a product is a limited edition on consumer behavior. In an experiment, the information limited edition was manipulated in a series of product descriptions presented to undergraduate students $(N=130)$. Results have indicated the effect of the expression's use on a consumer's willingness to pay for a product and purchase intention. Individuals exposed to the information that products were in limited editions attributed superior values to them and, in certain cases, higher purchase intention in the 30 following days, compared to consumers who were not informed about the fact. Theoretical and managerial implications are discussed, emphasizing that the expression has a communicational effect on the valorization of products, but it does not necessarily implies in an increase of purchase intention.
\end{abstract}

Keywords: Limited Editions. Scarcity. Consumer behavior. Marketing strategy. Sales promotion. 


\section{INTRODUÇÃO}

Independentemente da sua localização na história ou seu nível de acessibilidade, os produtos de luxo possuem um atributo principal em comum: a exclusividade. A ideia de ser único, exclusivo, especial e diferente conduz a indústria do luxo (PAIXÃO, 2007). Contudo, existem organizações que se apropriam desse conceito de exclusividade e o utilizam estrategicamente com o intuito de persuadir os consumidores. Esses produtos não fazem parte formal do universo dos bens de luxo. Eles habitam um espaço entre a produção massificada e a raridade. Englobam características de ambas as esferas, criando, assim, uma categoria própria, formada por itens escassos, que são ofertados durante tempo e/ou quantidade restritos: são as edições limitadas.

Quanto à origem de sua utilização como ferramenta mercadológica na comercialização, parece existir uma relação entre a história comercial dos livros e os atuais produtos produzidos em quantidades limitadas. Na sua história comercial, era comum a produção de livros em edições de luxo, o que Martins (2002) aponta como sendo a transformação do livro em simples objeto de comércio. "Por sua tiragem restrita, seu preço elevado e também pelas audácias que contêm, os livros de luxo se destinam, a despeito do seu número crescente, a uma clientela limitada.” (MARTINS, 2002, p. 247). Não existem registros formais que comprovem que as organizações utilizaram o conceito de exclusividade dos livros de luxo como estratégia para os primeiros produtos comercializados em edições limitadas. Independente disso, o livro em edição de luxo parece ser a forma mais antiga encontrada de um produto em que se utilizem características inerentes das edições limitadas em suas estratégias comerciais para despertar estímulos de compra por parte dos consumidores.

Apesar de as edições limitadas estarem presentes no mercado desde o surgimento dos livros como objetos comerciais, observa-se, na literatura revisada na seção seguinte, algumas lacunas de conhecimento na área: A simples informação de que um produto encontra-se em edição limitada (escassez por abastecimento limitado não por alta demanda) tem um impacto real sobre o comportamento do consumidor? Além disso, observando os estudos de Van Herpen, Pieters e Zeelenberg (2014), que apontaram o envolvimento como determinante no efeito, seria esse efeito da simples informação de que um produto se encontra em edição limitada observado no contexto dos produtos preferidos do consumidor, com os quais ele teria maior interesse e envolvimento? Respostas a essas lacunas auxiliariam não apenas a desenvolver conhecimento científico sobre o tema, mas também a compreender a relevância, em 
nível gerencial, da simples exposição da informação de que o produto se encontra em edição limitada sobre o consumidor. Sabe-se que, em diversos contextos, poderia ser interessante trabalhar apenas com uma estratégia comunicacional com produto, o que justifica, também, a relevância aplicada do presente estudo.

Com o objetivo de avaliar o impacto do uso da informação de que um produto se trata de uma edição limitada sobre as percepções do consumidor em relação a valor estimado do produto, disposição para pagar por ele e intenção de compra, foi delineado o experimento relatado no presente artigo. A seguir, encontra-se a revisão da base teórica que originou a pesquisa, possibilitando a formulação das hipóteses, apresentadas ao final do artigo.

\section{FUNDAMENTAÇÃO TEÓRICA}

Cialdini (2006) afirma que a escassez pode ser utilizada como ferramenta de persuasão, atuando nos pontos frágeis da natureza humana de respostas a estímulos e padrões de comportamento. A chamada "regra dos poucos” age com grande força sobre o valor que as pessoas atribuem às coisas. Segundo esse conceito, o valor das oportunidades parece aumentar à medida que elas se tornam restritas. É possível observar mais claramente este fenômeno quando examinado o caso dos colecionadores. Geralmente, quando um item é raro, ou tende a ficar raro, seu valor é maior. Ironicamente, um produto pode possuir alguma irregularidade ou defeito - o que em outro momento o tornaria descartável - e, por causa dessa característica peculiar e escassa, tornar-se valioso (CIALDINI, 2006).

O poder do princípio da escassez reside em duas principais vertentes. A primeira está ligada à fraqueza dos indivíduos por utilizar atalhos (ou heurísticas). A ideia intrínseca que os indivíduos possuem de atribuir maior valor às coisas que são difíceis de obter em detrimento às fáceis se torna um atalho para determinar rapidamente a qualidade de algum item. Assim, o que fortalece essa primeira vertente da escassez é o fato de, geralmente, o indivíduo estar certo ao utilizar essa forma de atalho. A segunda vertente trata da perda de liberdade. Conforme uma oportunidade tende a se tornar escassa, os sujeitos perdem a autonomia para aproveitá-la, o que não agrada nenhum deles. Assim, a vontade das pessoas em manter essa independência é o centro da teoria da reatância psicológica, que aborda a reação das pessoas à redução do seu controle. Essa teoria afirma que, quando a liberdade de escolha de um indivíduo é limitada ou ameaçada, a vontade de preservar a autonomia faz com que ele a deseje - e os produtos e serviços associados à escolha - mais que antes. Portanto, assim que a escassez 
intervém no acesso a algum item, a tendência do sujeito é reagir e almejar a posse do item de forma mais intensa que a anterior (CIALDINI, 2006).

Quando a liberdade de possuir algo é limitada, esse item se torna menos disponível, e as pessoas tendem a ter desejo maior por ele. Contudo, raramente reconhecem que a reatância psicológica fez querer mais esse item; tudo o que sabem é que o querem. Ainda assim, é preciso dar sentido ao desejo pelo item, então, os consumidores começam a atribuir qualidades positivas que justificam o desejo, afinal, é natural supor que, quando se sentem atraídos por algo, é por causa de seu mérito (CIALDINI, 2006).

Valendo-se desses conhecimentos, a promoção de vendas, como estratégia de marketing, pode fazer o uso de incentivos de curto prazo para promover o incremento de vendas. Kotler (2000) reforça essa ideia de maneira clara e objetiva ao afirmar que a promoção de vendas é projetada para o estímulo de compras mais rápidas ou em quantidades maiores em um período menor de tempo. Para tal, podem ser utilizadas diversas ferramentas, como amostras, cupons, brindes, prêmios ou qualquer forma de incitar e impulsionar a venda limitando a decisão do consumidor pelo rápido prazo ou pouca disponibilidade do produto ou serviço.

As organizações ofertam, assim, produtos em quantidades limitadas, com o intuito de criar escassez e, com isso, persuadir o consumidor a escolher o produto por causa de sua raridade e exclusividade. Movendo-se do campo teórico para a observação de estudos empíricos experimentais sobre o tema, pode-se observar que Byun e Sternquist (2012) corroboram essa ideia ao identificar que, quando existe uma limitação da disponibilidade de um item, a tendência do indivíduo é adquiri-lo, mesmo não tendo a certeza de que deve ou não comprá-lo. A relação entre escassez e preço percebido, no entanto, não parece simples.

Em relação ao preço imaginado de produtos pelo consumidor, Lynn (1989) detectou que a escassez aumenta o grau em que um produto é desejado no contexto de gravuras artísticas, mas apenas quando o consumidor foi levado a pensar previamente sobre preços da categoria em geral. O mesmo ocorreu em relação ao vinho, quando as pessoas desconheciam preços desses produtos.

A simples baixa disponibilidade de um produto, no entanto, não é suficiente para explicar essa relação com percepção de preço. Verhallen e Robben (1994), por exemplo, ratificaram o poder da escassez em relação às preferências do consumidor, detectando que livros com disponibilidade limitada em razão de circunstâncias de mercado foram percebidos como mais caros e únicos que aqueles acidentalmente indisponíveis. Parker e Lehmann (2011), no entanto, detectaram que a simples escassez 
de um produto na prateleira (no caso, vinhos) afeta a preferência do consumidor, demonstrando que popularidade, mais que qualidade, é um drive primário do efeito.

Na mesma direção, Gierl e Huettl (2009) investigaram o efeito de dois tipos de escassez nas atitudes do consumidor em relação a produtos: escassez de suprimento (edições limitadas) e escassez em decorrência da demanda (indisponibilidade, perante um número reduzido de itens). Segundo os autores, o efeito da escassez depende da percepção de que o produto é para consumo conspícuo. Se usado como produto ostentatório, a escassez por suprimento limitado é mais vantajosa, quando comparada à escassez por alta demanda do item. O oposto ocorre com produtos para consumo não conspícuo: escassez por demanda é mais favorável.

Resultados na mesma direção foram observados em experimentos prévios de Verhallen (1982). A escassez teve o efeito esperado apenas para produtos considerados atrativos pelas pessoas. Sujeitos não atraídos pelos produtos evitaram realizar a escolha, o que demonstra a importância de se considerar que o efeito da escassez pode ser o reverso do esperado em um público com preferências pouco definidas.

Similarmente, Ku et al. (2011) demonstraram que, nas compras por produtos utilitários, as pessoas são mais inclinadas a responder positivamente à escassez gerada por demanda do produto que por abastecimento limitado. O oposto foi observado para produtos hedônicos.

O caráter não universal do efeito da escassez sobre o comportamento do consumidor foi trazido em um recente estudo por Van Herpen, Pieters e Zeelenberg (2014). Os autores demonstraram, experimentalmente, entre outros efeitos, que a escassez tem pouco ou nenhum efeito quando os consumidores são pouco envolvidos com dada categoria de produtos (neste caso, vinhos). Indicaram, ainda, que a escassez é efetivamente comunicada não apenas de forma verbal em vendas, mas que a mera indisponibilidade ou espaços vazios na prateleira são indicadores de alta demanda.

Wu et al. (2012) indicam, a partir de seus experimentos, que existem diferenças dos influenciadores de intenção de compra e de percepção de preço. A intenção de compra sugeriu ser influenciada por exclusividade e sacrifício percebidos. Por outro lado, a percepção de valor foi mais forte diante da percepção de preço (alto), qualidade percebida, sacrifício e valor percebidos.

No que se refere aos anúncios publicitários sobre a escassez, Aguirre-Rodriguez (2013) investigou as diferenças entre escassez por demanda ou por suprimento. Propagandas enfatizando escassez por suprimento (edição limitada) são menos persuasivas em relação às que evidenciam alta demanda. O apelo específico - em 
oposição ao vago - nas mensagens publicitárias decrescem o grau de persuasão em apelos de escassez.

Com base na revisão de literatura realizada, as hipóteses da pesquisa são que a simples exposição da informação edição limitada tem impacto na percepção de (H1) valor estimado, de modo que o consumidor relatará maior diferença entre o valor que está disposto a pagar pelo produto e o preço “usual” estimado em uma edição comum; (H2) intenção de compra sem tempo delimitado por parte dos consumidores, já que ela aumentará perante o uso da informação de que o produto consiste em uma edição limitada; e (H3) intenção de compra em curto prazo definido (30 dias), de modo que a intenção de compra aumentará perante o uso da informação edição limitada. O experimento, delineado para atingir os objetivos propostos e testar as hipóteses aqui levantadas, encontra-se detalhado na seção seguinte.

\section{MÉTODO}

\subsection{PLANO EXPERIMENTAL}

O experimento teve, como variável independente, a presença/ausência da informação de que dados produtos se tratavam de edições limitadas, o que gerou dois grupos de participantes, sendo um o grupo controle (não exposto a tal informação) e o outro, o grupo experimental. As variáveis dependentes mensuradas foram valor estimado dos produtos, disposição de valor para pagar por eles e intenção de compra em relação a cada um.

\subsection{AMOSTRA E AMOSTRAGEM}

A amostra foi composta por 130 estudantes de uma universidade particular de Porto Alegre, cujos alunos são predominantemente de Classes A e B. Os integrantes (71 indivíduos do sexo feminino e 59 do sexo masculino) foram estudantes do primeiro ano dos cursos de Publicidade e Propaganda e Relações Internacionais. Sua média de idade foi de 18,37 anos ( $\mathrm{DP}=1,15$ anos). Eles foram divididos em dois grupos em razão da variável independente (informação de o produto ser uma edição limitada). O grupo controle ( $n=54)$, que não foi exposto à informação de que os produtos avaliados se tratavam de edições limitadas, e o grupo experimental (n=76), exposto à comunicação do caráter limitado dos produtos, tiveram seus membros distribuídos de maneira não probabilística e por conveniência. 


\subsection{MATERIAIS E PROCEDIMENTOS PARA A COLETA DE DADOS}

Inicialmente, para o desenvolvimento do instrumento, foram realizadas pesquisas em sítios da Internet para identificar os principais produtos que produziram versões em edição limitada. Os resultados, então, foram agrupados em quatro categorias - veículos (automóvel, motocicleta), cultura (CD, DVD, livro), entretenimento (jogo de vídeogame ou computador, vídeogame) e artigos pessoais (perfume, relógio de pulso), totalizando nove produtos.

Foram criadas nove afirmativas para a condição experimental, apresentando situações de compra de cada produto. Enquanto para os integrantes do grupo controle foram apresentadas frases como "Considere você comprar o seu filme preferido em DVD” e para o grupo experimental apresentaram-se situações como "Considere que o seu filme preferido está lançando um DVD versão edição limitada”. Assim, foram gerados dois questionários: um para o grupo controle e outro para o experimental.

Em ambas as condições - controle e experimental - a instrução foi que a pessoa pensasse em seus produtos preferidos. Conforme salientado na introdução do presente artigo, os estudos de Van Herpen, Pieters e Zeelenberg (2014) apontaram o envolvimento como determinante no efeito avaliado. Apenas entre produtos atrativos para os públicos o efeito da escassez criada pela ideia de uma edição limitada seria detectado (VERHALLEN, 1982), o que seria condição fundamental para o sucesso da manipulação experimental proposta.

Logo após a frase de apresentação da situação, a pessoa deveria escrever em qual produto pensou (qual filme ou livro, por exemplo), a fim de servir como base para as demais questões. Cada situação apresentada foi acompanhada por duas perguntas abertas (referentes a valores estimados dos produtos) e duas fechadas (relativas à intenção de compra).

As questões abertas abordaram a avaliação de valor monetário - preço. No grupo controle, o indivíduo respondeu sobre a sua ideia de valor para o produto em uma edição comum (Qual o valor que você imagina que ele custa (em reais)?) e, em seguida, relatou qual o valor máximo que estaria disposto a pagar pelo produto em questão em edição comum (Qual o valor máximo que você pagaria por ele (em reais)?). No grupo experimental, primeiro o respondente indicou sua avaliação de preço do produto imaginado em edição comum (Qual o valor que você imagina que custaria a edição normal (em reais)?) e, em seguida, estimou o valor da edição limitada (Qual o valor máximo que você pagaria por esta edição limitada (em reais)?). 
As questões fechadas abordaram a intenção de compra sem prazo determinado (Qual a probabilidade de você comprar este produto?) e com um prazo determinado de 30 dias (Qual a probabilidade de você comprar este produto nos próximos 30 (trinta) dias?) de forma idêntica em ambos os grupos - controle e experimental. Foram utilizadas escalas do tipo Likert de cinco pontos para mensurar a intenção de compra dos produtos por parte dos respondentes - um para definitivamente não compraria, dois para provavelmente não compraria, três para poderia ou não comprar, quatro para provavelmente compraria e cinco para definitivamente compraria.

A última etapa da elaboração do instrumento de pesquisa foi a realização de um pré-teste com, aproximadamente, $10 \%$ da amostra. A avaliação evidenciou a adequação dos questionários em termos de linguagem e conteúdo.

Para a coleta definitiva dos dados, a direção da instituição de ensino na qual a pesquisa foi realizada autorizou os pesquisadores a realizarem o projeto. A aplicação dos questionários foi realizada na modalidade impressa e ocorreu em momentos de aula dos estudantes. Os alunos foram informados da decisão e do caráter voluntário e anônimo de participação na pesquisa. Os participantes foram orientados a responder de forma individual e, se houvesse falta de interesse em relação a algum produto, a questão não deveria ser respondida. Também foi solicitado aos alunos que não pensassem em produtos ilegais ou piratas.

\subsection{PROCEDIMENTOS PARA A ANÁLISE DOS DADOS}

As respostas, coletadas em papel, foram digitadas em um banco de dados. Para a análise dos dados, foi utilizado o programa Statistical Package for the Social Sciences (SPSS).

As perguntas sobre o quanto pagariam pelo produto imaginado (Qual o valor máximo que você pagaria por ele (em reais)? - para o grupo controle - e Qual o valor máximo que você pagaria por esta edição limitada (em reais)? - para o grupo experimental), divididas pelas questões sobre o valor atribuído ao produto (Qual o valor que você imagina que ele custa (em Reais)? - para o grupo controle - e Qual o valor que você imagina que custaria a edição normal (em reais)? - para edição limitada), redundam em uma proporção. A fim de facilitar a visualização dos resultados na seção seguinte, denominou-se essa proporção de D/E (disposição para pagar dividida pela estimativa de valor real). Por meio do Teste t de duas caudas para amostras independentes, são obtidos os valores do teste de hipótese entre as diferenças das médias das respostas $\mathrm{D} / \mathrm{E}$ dadas pelo grupo controle e pelo grupo experimental. 
Foi utilizado o Teste t, também, para avaliar as diferenças de médias entre os grupos controle e experimental na análise da questão sobre intenção de compra sem tempo determinado para a compra (Qual a probabilidade de você comprar este produto?). A mesma técnica foi aplicada para análise da intenção de compra estimada em 30 dias (Qual a probabilidade de você comprar este produto nos próximos 30 (trinta) dias?).

\section{RESULTADOS}

A Tabela 1 expressa as médias D/E (disposição para pagar dividida pela estimativa de valor real) em edições limitada e comum.

Tabela 1 - Médias e desvios padrão dos valores reais estimados dos produtos e a disposição para pagar por eles (em edição limitada e comum)

\begin{tabular}{|c|c|c|c|c|c|}
\hline Categoria & Produto & Edição & N. & Média & DP \\
\hline \multirow{4}{*}{ Veículos } & \multirow{2}{*}{ Automóvel } & Comum & 52 & 1,20 & 0,37 \\
\hline & & Limitada & 72 & $1,36^{*}$ & 0,39 \\
\hline & \multirow{2}{*}{ Motocicleta } & Comum & 29 & 1,20 & 0,30 \\
\hline & & Limitada & 47 & $1,44^{* *}$ & 0,47 \\
\hline \multirow{6}{*}{ Cultura } & \multirow{2}{*}{ CD } & Comum & 52 & 1,25 & 0,43 \\
\hline & & Limitada & 71 & $2,02 * *$ & 0,89 \\
\hline & \multirow{2}{*}{ DVD } & Comum & 51 & 1,24 & 0,52 \\
\hline & & Limitada & 63 & $1,67 * *$ & 0,63 \\
\hline & \multirow{2}{*}{ Livro } & Comum & 49 & 1,34 & 0,35 \\
\hline & & Limitada & 55 & $1,68 * *$ & 0,58 \\
\hline \multirow{4}{*}{ Entretenimento } & \multirow{2}{*}{$\begin{array}{l}\text { Jogo de videogame ou jogo de } \\
\text { computador }\end{array}$} & Comum & 28 & 1,26 & 0,52 \\
\hline & & Limitada & 47 & $1,53^{*}$ & 0,43 \\
\hline & \multirow{2}{*}{ Videogame } & Comum & 35 & 1,14 & 0,50 \\
\hline & & Limitada & 45 & $1,48 * *$ & 0,45 \\
\hline \multirow{4}{*}{ Artigos pessoais } & \multirow{2}{*}{ Perfume } & Comum & 48 & 1,26 & 0,52 \\
\hline & & Limitada & 61 & $1,68^{*}$ & 1,17 \\
\hline & \multirow{2}{*}{ Relógio de pulso } & Comum & 45 & 1,24 & 0,46 \\
\hline & & Limitada & 48 & $1,57 * *$ & 0,48 \\
\hline
\end{tabular}

Nota:* $\mathrm{p}<0,05 ; * * \mathrm{p}<0,01$

Fonte: os autores.

Foi detectado o efeito da variável independente - informação edição limitada - sobre D/E, uma vez que, para todos os produtos investigados, as diferenças das médias dos produtos em edição limitada e edição comum foram diferentes, de modo que foram expressivamente maiores no caso dos primeiros. 
Detectou-se o efeito investigado em todas as categorias - veículos, cultura, entretenimento e artigos pessoais: Automóvel t(113,231)=-2,415, $\mathrm{p}<0,05$; Motocicleta $\mathrm{t}(73,939)=-2,666, \mathrm{p}<0,01$; CD t(106,953)=-6,317, $\mathrm{p}<0,001$; DVD t(111,990)=4,003, $\mathrm{p}<0,001$; Livro $\mathrm{t}(89,916)=-3,697, \mathrm{p}<0,001$; Jogo de vídeogame ou jogo de computador $\mathrm{t}(48,175)=-2,343, \mathrm{p}<0,05$; Vídeogame $\mathrm{t}(68,886)=-3,195, \mathrm{p}<0,01$; Perfume $t(87,207)=-2,529, p<0,05$; Relógio de pulso $t(90,882)=-3,383, p<0,001$. Em todas elas, as médias das edições limitadas foram significativamente superiores às das edições comuns.

Em relação à intenção de compra sem tempo determinado, na Tabela 2 se apresentam os resultados para cada um dos produtos em edição comum e edição limitada.

Tabela 2 - Médias e desvios padrão da intenção de compra entre edições limitadas e edições comuns sem prazo de tempo estipulado

\begin{tabular}{|c|c|c|c|c|c|}
\hline Categoria & Produto & Edição & $\mathrm{N}$ & Média & DP \\
\hline \multirow{4}{*}{ Veículos } & \multirow{2}{*}{ Automóvel } & Comum & 72 & 3,31 & 1,086 \\
\hline & & Limitada & 29 & 2,96 & 0,926 \\
\hline & \multirow{2}{*}{ Motocicleta } & Comum & 47 & 2,45 & 1,183 \\
\hline & & Limitada & 51 & 2,15 & 0,908 \\
\hline \multirow{6}{*}{ Cultura } & \multirow{2}{*}{ CD } & Comum & 70 & 4,04 & 1,131 \\
\hline & & Limitada & 49 & 4,04 & 0,970 \\
\hline & \multirow{2}{*}{ DVD } & Comum & 63 & 3,98 & 1,010 \\
\hline & & Limitada & 49 & 3,68 & 1,075 \\
\hline & \multirow{2}{*}{ Livro } & Comum & 55 & 4,10 & 1,085 \\
\hline & & Limitada & 28 & 3,73 & 1,096 \\
\hline \multirow{4}{*}{ Entretenimento } & \multirow{2}{*}{$\begin{array}{l}\text { Jogo de video game ou jogo de } \\
\text { computador }\end{array}$} & Comum & 47 & 3,57 & 1,260 \\
\hline & & Limitada & 33 & 3,43 & 1,037 \\
\hline & \multirow{2}{*}{ Video game } & Comum & 45 & 3,39 & 1,197 \\
\hline & & Limitada & 47 & 3,00 & 1,087 \\
\hline \multirow{4}{*}{ Artigos pessoais } & \multirow{2}{*}{ Perfume } & Comum & 61 & 4,26 & 0,920 \\
\hline & & Limitada & 45 & $3,80^{*}$ & 0,928 \\
\hline & \multirow{2}{*}{ Relógio de pulso } & Comum & 47 & 3,71 & 1,036 \\
\hline & & Limitada & 72 & 3,30 & 1,121 \\
\hline
\end{tabular}

Nota: ${ }^{*} \mathrm{p}<0,05 ; * * \mathrm{p}<0,01$

Fonte: os autores.

Foi detectado o efeito da variável independente apenas no produto Perfume, $(t(99,492)=2,522, p<0,05)$. O efeito, vale ressaltar, revelou que a média das edições comuns foi superior. 
A Tabela 3, por sua vez, expressa a comparação de médias da intenção de compra determinando um prazo máximo de 30 dias para que ela aconteça.

Tabela 3 - Médias e desvio padrão da intenção de compra entre edições limitadas e edições comuns com prazo de tempo estipulado (30 dias).

\begin{tabular}{|c|c|c|c|c|c|}
\hline Categoria & Produto & Edição & $\mathrm{N}$ & Média & DP \\
\hline \multirow{4}{*}{ Veículos } & \multirow{2}{*}{ Automóvel } & Comum & 51 & 1,22 &, 541 \\
\hline & & Limitada & 71 & $1,75^{* *}$ & 921 \\
\hline & \multirow{2}{*}{ Motocicleta } & Comum & 29 & 1,14 & 351 \\
\hline & & Limitada & 47 & $1,49 * *$ & ,718 \\
\hline \multirow{6}{*}{ Cultura } & \multirow{2}{*}{$\mathrm{CD}$} & Comum & 51 & 3,24 & 1,210 \\
\hline & & Limitada & 70 & $3,77 * *$ & 1,144 \\
\hline & \multirow{2}{*}{ DVD } & Comum & 48 & 3,27 & 1,250 \\
\hline & & Limitada & 63 & 3,46 & 1,268 \\
\hline & \multirow{2}{*}{ Livro } & Comum & 48 & 3,33 & 1,155 \\
\hline & & Limitada & 55 & 3,25 & 1,322 \\
\hline \multirow{4}{*}{ Entretenimento } & \multirow{2}{*}{$\begin{array}{l}\text { Jogo de video game ou jogo de } \\
\text { computador }\end{array}$} & Comum & 28 & 2,79 & 1,397 \\
\hline & & Limitada & 47 & 2,81 & 1,296 \\
\hline & \multirow{2}{*}{ Video game } & Comum & 33 & 1,97 & 1,045 \\
\hline & & Limitada & 45 & 2,40 & 1,156 \\
\hline \multirow{4}{*}{ Artigos pessoais } & \multirow{2}{*}{ Perfume } & Comum & 47 & 2,91 & 1,176 \\
\hline & & Limitada & 61 & $3,38 *$ & 1,143 \\
\hline & \multirow{2}{*}{ Relógio de pulso } & Comum & 45 & 2,18 & 1,007 \\
\hline & & Limitada & 47 & 2,55 & 1,299 \\
\hline
\end{tabular}

Nota:* $\mathrm{p}<0,05 ; * * \mathrm{p}<0,01$

Fonte: os autores.

O efeito da variável independente sobre as diferenças de intenção de compra foi identificado em quatro dos nove produtos testados: Automóvel $(\mathrm{t}(115,919)=-$ 3,990, $\mathrm{p}<0,001)$, Motocicleta $(\mathrm{t}(71,009)=-2,848, \mathrm{p}<0,01), \mathrm{CD}(\mathrm{t}(104,310)=-2,463$, $\mathrm{p}<0,05)$ e Perfume $(\mathrm{t}(97,628)=-2,050, \mathrm{p}<0,05)$ dos nove testados.

\section{DISCUSSÃO}

Mesmo não possuindo todas as características dos bens de luxo, as edições limitadas carregam a aura de exclusividade referida por Paixão (2007). Essa ideia de ser único e restrito está diretamente ligada por meio da escassez às estratégias de persuasão. Os profissionais de marketing verificaram, na possibilidade de recriar a escassez, uma oportunidade de vencer o problema do excesso de oferta. 
Na corrente pesquisa, o estudo das edições limitadas apontou que existe um impacto na percepção do consumidor quando a mensagem apresentada foi construída com elementos persuasivos, independente do produto ou marca imaginado pelo indivíduo. Destaca-se o fato de ser possível afirmar que a manipulação da expressão edição limitada tende a causar um efeito na diferença entre os valores percebidos em produtos de diversas categorias e a disposição dos consumidores para pagar por eles, bem como em sua intenção de compra.

Assim, foi possível aceitar a H1, já que o efeito esperado foi encontrado na avaliação de todos os produtos. A diferença entre o valor que o consumidor estaria disposto a pagar e o valor estimado em uma situação usual de consumo de produtos em edições limitadas tendeu a ser superior em relação a edições comuns.

No entanto, a aceitação das hipóteses relativas à intenção de compra não foi absoluta. Na intenção de compra sem tempo determinado (H2), foi detectado efeito do uso do termo edição limitada para apenas um produto, e a maior intenção de compra ocorreu para edições comuns - o contrário do esperado. Quando o prazo de 30 dias foi estabelecido (H3), no entanto, o efeito foi detectado para quatro dos nove produtos avaliados, o que representa uma oportunidade de pesquisa futura, já que não foi um efeito totalmente consistente como o detectado em relação à variável preço. Vale ressaltar que, para ambos os produtos de maior valor agregado (veículos), foi detectado o efeito. Mesmo que baseada apenas na literatura revisada na introdução do presente artigo, vale a ponderação de que, talvez, o valor percebido nos produtos e o consequente maior envolvimento com uma possível compra poderiam ser a chave para explicar a inconsistência dos resultados para alguns produtos e deveriam ser contemplados em futuras investigações.

Os profissionais de marketing verificaram, na possibilidade de recriar a escassez, uma oportunidade de vencer o problema do excesso de oferta. Com as estratégias de quantidades limitadas, é visível o impacto no valor percebido por parte dos indivíduos. Foi possível notar que a "regra dos poucos” (CIALDINI, 2006) pode ser observada mesmo em um contexto experimental extremamente artificial que, intencionalmente, isolou a simples presença da expressão de que o produto em análise pelo consumidor se tratava de uma edição limitada. A simples informação, portanto, mostrou-se uma importante ferramenta de persuasão para a comunicação, na medida em que os indivíduos atribuíram maior valor a produtos que seriam difíceis de obter e afirmaram maior intenção de compra, mesmo que não para todos os produtos avaliados, garantindo sua liberdade como consumidores, como sugere o autor. 
Os dados ratificam, também, os resultados de Byun e Sternquist (2012), já que a baixa disponibilidade de um item aumentou sua intenção de compra (neste caso, em prazo reduzido de 30 dias), e os de Lynn (1989) e Verhallen e Robben (1994) em relação ao aumento do preço imaginado perante a escassez.

Da mesma forma que Parker e Lehmann (2011) detectaram que a simples escassez do produto na prateleira afetou a preferência dos consumidores, o presente estudo detectou que a simples informação edição limitada teve efeito similar, de modo que apenas indicar a possibilidade da falta funciona como um drive primário do efeito em estudo.

Como no experimento relatado neste artigo se trabalhou com os produtos preferidos dos respondentes, vale ressaltar, ainda, em consonância com os resultados encontrados por Ku et al. (2011), que a demanda por abastecimento limitado gerou efeitos sobre a percepção de preço e a intenção de compra na aquisição de produtos que podem ser considerados, em razão da preferência, com uma função hedônica, mesmo que também possam ter uma função utilitária.

O achado é também ratificado pelos resultados de Van Herpen, Pieters e Zeelenberg (2014), já que a escassez geraria um efeito mais consistente sobre o consumidor quando fosse mais envolvido com os produtos em questão. Acredita-se que o fato de trabalhar com produtos preferidos pelas pessoas tenha possibilitado a detecção dos efeitos apontados.

A exclusividade dos produtos, expressa na forma de sua apresentação no presente experimento, como no estudo de Wu et al. (2012), parece ter sido um motivador da intenção de compra. Mesmo que não seja verdade para todos os produtos, é válido ratificar que os consumidores, para diversos produtos avaliados, tiveram intenções de compra aumentadas diante da informação de que se tratavam de edições limitadas.

\section{CONCLUSÃO}

Os resultados do presente estudo possibilitam o desenvolvimento de uma base mais sólida para embasar a utilização de produtos em edições limitadas, já que se detectou a existência do impacto da expressão edição limitada na percepção do consumidor sobre a diferença entre os preços percebidos nos produtos e a disposição para pagar por eles, assim como nas intenções de compra. Suas aplicações podem ser tanto na esfera acadêmica quanto na profissional.

No âmbito acadêmico, é evidente a identificação da força que uma simples expressão - edição limitada - tem sobre o comportamento do consumidor. Assim, 
percebe-se a contribuição teórica para a compreensão dos aspectos comunicacionais da expressão edição limitada em Marketing.

No universo profissional, vale observar que apenas o uso da expressão edição limitada na comunicação de um produto aumenta o gap entre o valor (D/E) em uma edição comum e a que se apresenta como limitada, apesar de não garantir aumento da intenção de compra. Assim, o efeito comunicacional da expressão tem impacto em termos da valorização do produto, mas não implica, necessariamente, uma tendência comportamental para a compra.

As limitações do presente estudo residem, primeiramente, no fato de a sua realização ter se ocorrido em um ambiente artificial. No entanto, foi o cenário ideal para isolar o efeito da simples informação de que os produtos se encontravam em edições limitadas, possibilitando um estudo apenas do aspecto comunicacional da variável. Em segundo lugar, a amostra é específica e composta por indivíduos com características extremamente delineadas.

Nessa direção, indica-se, como caminhos para estudos futuros, a realização de estudos em ambientes naturais e situações cotidianas de consumo. Da mesma forma, aponta-se a necessidade de novas pesquisas que contemplem a diversidade de características sociais e demográficas da população.

\section{REFERÊNCIAS}

AGUIRRE-RODRIGUEZ, A. The effect of consumer persuasion knowledge on scarcity appeal persuasiveness. Journal of Advertising, v. 42, i. 4, p. 371-379, Oct. 2013.

BYUN, S.; STERNQUIST, B. Here Today, Gone Tomorrow: Consumer Reactions to Perceived Limited Availability. Journal of Marketing Theory \& Practice, v. 20, p. 223-234, Apr. 2012.

CIALDINI, R. B. O poder da persuasão: você pode ser mais influente do que imagina. Rio de Janeiro: Elsevier, 2006.

GIERL, H.; HUETTL, V. Are scarce products always more attractive? The interaction of diferent types of scarcity signals with products' suitability for conspicuous consumption. International Journal of Research in Marketing, v. 27, p. 225-235, Sept. 2010.

KOTLER, P. Administração de marketing. São Paulo: Prentice Hall, 2000. 
KU, H. et al. Decision-contextual and individual influences on scarcity effects. European Journal of Marketing, v. 47, i. 8, p. 1314-1332, Sept. 2011.

LYNN, M. Scarcity effects on desirability: Mediated by assumed expensiveness? Journal of Economic Psychology, v. 10, p. 257-274, June 1989.

MARTINS, W. A palavra escrita. São Paulo: Ática, 2002.

PAIXÃO, L. O supérfluo indispensável. Revista View, v. 77, p. 1-11, jan. 2007.

PARKER, J. R.; LEHMANN, D. R. When shelf-based scarcity impacts consumer preferences. Journal of Retailing, v. 87, i. 2, p. 142-155, June 2011.

VAN HERPEN, E.; PIETERS, R.; ZEELENBERG, M. When less sells more or less: The scarcity principlein wine choice. Food Quality and Preference, v. 36, p. 153160, Sept. 2014.

VERHALLEN, T. M. M.; ROBBEN, H. S. J. Scarcity and preference: an experiment on unavailability and product evaluation. Journal of Economic Psychology, v. 15, p. 315-331, June 1994.

VERHALLEN, T. M. M. Scarcity and consumer choice behavior. Journal of Economic Psychology, v. 2, p. 299-322, Dec. 1982.

WU, W. et al. The effects of product scarcity and consumers' needs for uniqueness on purchase intention. International Journal of Consumer Studies, v. 36, p. 263274, May 2012. 
Como citar este artigo:

\section{ABNT}

SELAU, Sandro Dias; TONETTO, Leandro Miletto. Efeitos do uso da informação “Edição limitada sobre percepções de preço e intenção de compra de produtos.

RACE: Revista de Administração, Contabilidade e Economia, Joaçaba: Ed. Unoesc, v. 15, n. 1, p. 157-174, jan./abr. 2016. Disponível em: <http://editora.unoesc.edu.br/ index.php/race>. Acesso em: dia/mês/ano.

\section{APA}

SElau, S. D., \& Tonetto, L. M. (2016). Efeitos do uso da informação "Edição limitada sobre percepções de preço e intenção de compra de produtos. RACE: Revista de Administração, Contabilidade e Economia, 15(1), 157-174. Recuperado em dia/mês/ ano, de http://editora.unoesc.edu.br/index.php/race 
